\title{
Fatigue life improvement in fatigue-aged fastener holes using the cold expansion technique
}

\author{
X. Zhang ${ }^{\mathrm{a}^{*}}$ and Z. Wang ${ }^{\mathrm{b}}$ \\ ${ }^{\text {a }}$ School of Engineering, Cranfield University, Bedford, MK43 OAL, UK \\ ${ }^{b}$ Beijing Aeronautical Technology Institute, Beijing, 100076, P R China
}

\begin{abstract}
The use of cold expansion process as a life extension technique on aircraft structural joints was investigated. The primary focus was an experimental test programme consisting of open hole and low-load transfer joint specimens made of 2024-T351 aluminium alloy and pre-fatigued to $25 \%, 50 \%$ and $75 \%$ of the baseline fatigue life for plain holes. The FASTAFF loading spectrum was applied. The results indicate that significant life improvements can be obtained through cold expansion applied at all percentages of fatigue life tested in this work with the optimum stage being around $25 \%$ of the baseline life. The major life extension was obtained through slower crack growth in the short crack stage. The life improvement factors for the open-hole and joint specimens were comparable provided that the degree of cold expansion is the same. Crack growth life of the open-hole specimen was predicted by employing an analytical residual stress model and the AFGROW computer code. The prediction results showed good agreement with the experimental results for cold expansion at build cases.
\end{abstract}

Keywords: fastener holes, cold expansion, residual stress, fatigue crack growth, fatigue life prediction.

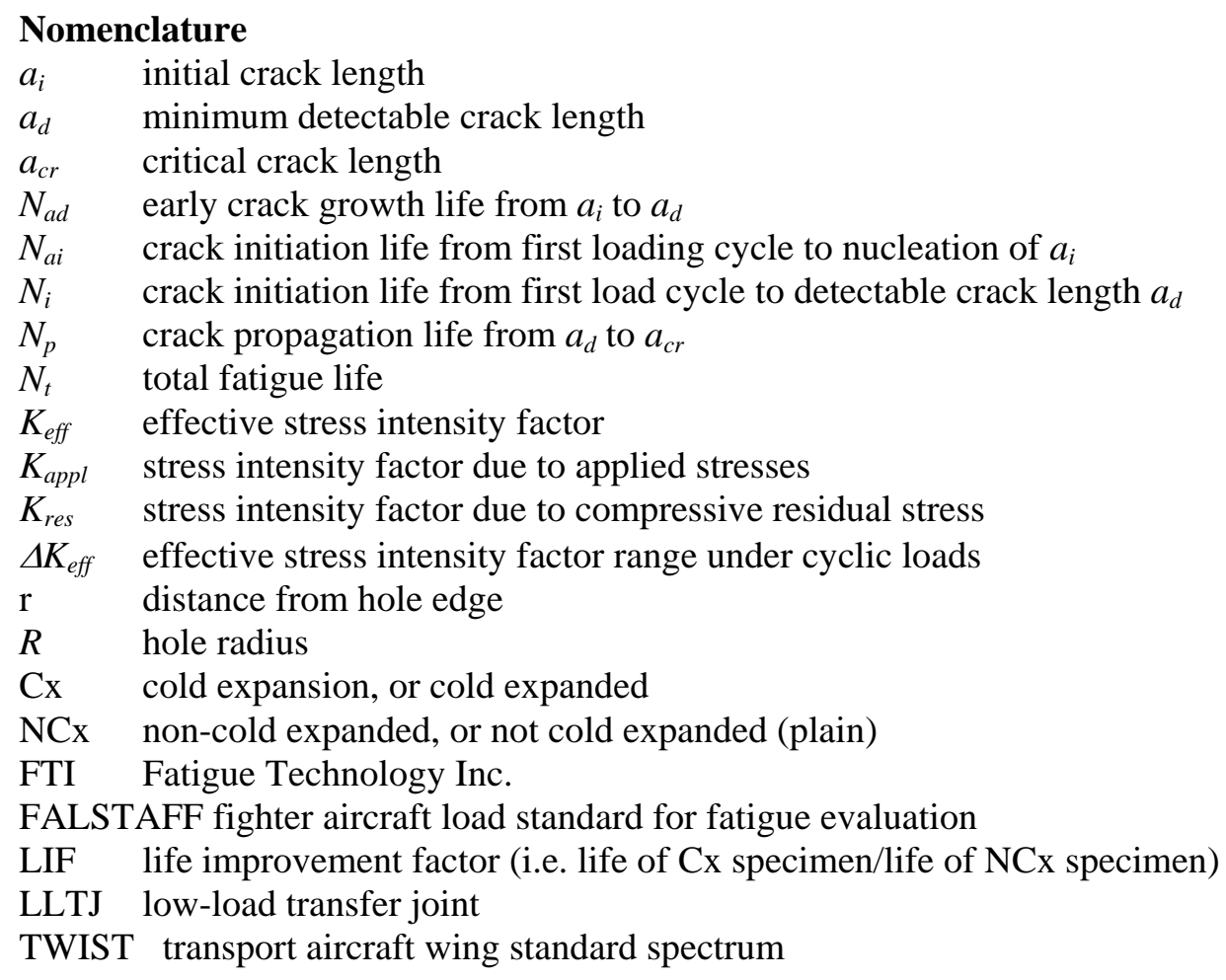

\section{Introduction}

The beneficial effect of cold expansion on fatigue life improvement of fastener joints needs no further introduction. The technique of cold expansion has been employed for over 40 years [1-4]. Of the numerous existing techniques, the split sleeve cold expansion method has been widely used in the aerospace industry and compares favorably with other techniques [5]. While cold expansion is being used increasingly for new aircraft to ensure that the service life of critical components meets or exceeds the

\footnotetext{
* Corresponding author. Fax: +44 1234 751550. Email address: xiang.zhang@cranfield.ac.uk (X. Zhang).
} 
required design life, the process may also be applied for in-service aircraft for repairing unanticipated fatigue damage or as a general means of life extension. Since the fastener holes of most existing aircraft were not cold expanded at build, there has been a drive to quantify the economic and structural benefits of cold expansion which is applied when an aircraft is part way through its service life. This strategy is particularly important to improve the cost effectiveness of operating ageing aircraft. Although there exist many published papers on life improvement of cold expanded holes in sheet structures, the available evidence on the benefit of cold expanding fatigue-aged fastener holes is limited. The state-of-the-art in this area is summarized below.

Wagner et al $[4,6]$ described a comprehensive test programme evaluating the benefits of cold expansion for open hole specimens made of two aerospace aluminium alloys, 2024-T3 and 7075-T6. While the paper focused on the rework process for pre-cycled holes that were cold expanded on production, it also looked at the effect of cold expanding fatigue-aged plain production holes. In the case of the 2024-T3 specimens, this part of the test was conducted under constant amplitude loading at two different stress levels. At the higher stress level (193 MPa), 30\% fatigue ageing of the plain hole specimens followed by cold expansion resulted in a seven-fold improvement in fatigue life over the plain hole specimens. Furthermore, for specimens that were not cold expanded on production, cold expansion in the first $50 \%$ of the baseline life resulted in fatigue lives up to $50 \%$ greater than cold expansion at build.

Buxbaum \& Huth [1] investigated cold expansion of joint specimens using both constant amplitude and standardized aircraft spectrum loads MINI-TWIST and FALSTAFF. Cold expansion was applied to fatigue-aged specimens after cycling to one of three predefined crack sizes: 1.0, 2.6, and $6.0 \mathrm{~mm}$. They found that the gain in fatigue life due to cold expansion decreased with increasing initial crack length; therefore cold expansion process should not be applied to crack lengths larger than the radius of the hole.

Cook [7] investigated repair of cracked fastener holes by cold expansion. He looked at low-load and medium-load transfer joints in four types of aluminium under the FALSTAFF loading at two different peak stress levels. Cold expansion was applied at a range of predefined crack lengths from 0.5 to $3.0 \mathrm{~mm}$. The results showed that the optimum enhancement occurred with cracks of less than about $1 \mathrm{~mm}$ present, but cold expansion was still effective at crack lengths up to $3.0 \mathrm{~mm}$.

The aim of the present work was to examine the effectiveness of cold expansion that is applied at a fraction of the total fatigue life of a non-cold expanded control specimen, irrespective of any fatigue cracks that may exist due to the fatigue pre-cycling. This simulates the practical situation of life enhancement for in-service aircraft that were not cold expanded on production and have expended a portion of their service lives prior to cold expansion. The program comprised two parts: experimental testing and theoretical life prediction. Experimental test was the primary objective with emphasis on the total fatigue lives to determine resulting life improvement factors (LIFs). Also of interest was the relative gains or losses in the crack initiation and crack growth lives, and the nature of the crack growth. Two geometrically similar specimens, open-hole and low-load transfer joint, were tested. The correlation between open hole and fastener hole results was also studied. The second part of this work focused on developing a model for predicting fatigue life of cold-worked holes to evaluate the benefits in both crack initiation and crack growth stages. Crack growth life prediction was performed using the AFGROW computer program and published residual stresses models.

\section{Experimental procedures}

\subsection{Specimens preparation}

A low-load transfer joint (LLTJ) specimen and an open-hole specimen of similar geometry were made of aluminium alloy 2024-T351. The joint specimen typically represents a span-wise attachment of aircraft wing panels, e.g. skin to stringers. This kind of joints is defined as those that have a load transfer between the members of less than $10 \%$ of the total axial load [11]. The joint specimen consisted of a reverse double dog-bone design as illustrated in Fig. 1. This design is based upon the standard AGARD 
(Advisory Group for Aerospace Research and Development) low-load transfer joint specimen for fastener evaluation [12]. The design resulted in only a small amount of secondary bending and a load transfer of approximately 5\% of the applied load through each of the fastener connections [12].

The test programme is shown in Table 1, which included non-cold expanded (NCx or plain hole) tests, cold expansion on production (Cx, or $0 \% \mathrm{Cx})$, and cold expansion at various percentages of fatigue lives (25\%Cx, 50\%Cx, and 75\% Cx) [8-10].

The FTI split sleeve cold expansion method [3-4] was used in this study. This is a form of mandrelizing which employs a lubricated sleeve as an interface between the mandrel and the hole. The expansion process consists of pulling an oversized tapered mandrel through the hole causing very high radial pressures to be exerted on the hole thus expanding the hole well beyond the yield strength of the material. This results in a zone of residual compressive stress that extends approximately one radius from the edge of the hole. The magnitude of the peak compressive residual stress is approximately equal to the yield strength of the material [3]. The cold expansion was always performed with the split in the sleeve (ridge) located in parallel to the load path, i.e. at the 3 o'clock position of the holes as seen in Fig. 1.

Table 1 Test programme and summary of results.

\begin{tabular}{|c|c|c|c|c|c|}
\hline $\begin{array}{l}\text { Sample } \\
\text { type }\end{array}$ & $\begin{array}{l}\text { Sample } \\
\text { number }\end{array}$ & Description & $\begin{array}{l}\text { Pre-cycle } \\
\text { before Cx } \\
\text { (Flights) } \\
\end{array}$ & $\begin{array}{l}\text { Total failure } \\
\text { life (Flights) }\end{array}$ & $\begin{array}{l}\text { Logarithm mean } \\
\text { life (Flights) }\end{array}$ \\
\hline \multirow[t]{5}{*}{$\begin{array}{l}\text { Open } \\
\text { hole }\end{array}$} & $\begin{array}{l}\text { NCx01 - } \\
\text { NCx05 }\end{array}$ & $\begin{array}{l}\text { Plain hole } \\
(\mathrm{NCx})\end{array}$ & 0 & $\begin{array}{l}\text { 7959, } 8580 \\
7592,7944, \\
7961 \\
\end{array}$ & 8001 \\
\hline & $\begin{array}{l}\text { Cx01- } \\
\text { Cx } 05\end{array}$ & Cx at build & 0 & $\begin{array}{l}\text { 24733, } 27688 \\
25603,30404\end{array}$ & 27021 \\
\hline & $\begin{array}{l}\text { 25\%Сx01 - } \\
25 \% \text { Сx05 }\end{array}$ & Cx at $25 \%$ life & 2000 & $\begin{array}{l}33281,35204 \\
31204,27203 \\
26403 \\
\end{array}$ & 30469 \\
\hline & $\begin{array}{l}50 \% \mathrm{Cx} 01- \\
50 \% \mathrm{Cx} 05\end{array}$ & $\mathrm{Cx}$ at $50 \%$ life & 4000 & $\begin{array}{l}\text { 25603, 21602, } \\
\text { 19202, } 22402 \\
(35204)^{*}\end{array}$ & 22086 \\
\hline & $\begin{array}{l}\text { 75\%Сx01 - } \\
75 \% \text { Сx03 }\end{array}$ & $\mathrm{Cx}$ at $75 \%$ life & 6000 & $\begin{array}{l}\text { 21603, } 14402 \\
(5601)^{*}\end{array}$ & 17639 \\
\hline \multirow[t]{7}{*}{ LLTJ } & J04 - J06 & Plain hole & N/A & $\begin{array}{l}10680 \\
9211,9759\end{array}$ & 9865 \\
\hline & J03* & Cx at Build & 0 & 17,572 & 17572 \\
\hline & J07, J08 & Cx at build & 0 & 32324, 35772 & 34004 \\
\hline & $\mathrm{J} 11, \mathrm{~J} 12$ & Cx at $25 \%$ life & 2400 & 31631, 39031 & 35137 \\
\hline & J09, J10 & Cx at $50 \%$ life & 5000 & 21972, 26129 & 23961 \\
\hline & J13, J14 & $\mathrm{Cx}$ at $75 \%$ life & 7400 & 21029, 13372 & 16769 \\
\hline & $\begin{array}{l}\text { J15 } \\
\text { Control test }\end{array}$ & $\begin{array}{l}\text { Plain hole } \\
\text { cleaned \& } \\
\text { reassembled at } \\
75 \% \text { life }\end{array}$ & N/A & 11372 & 11372 \\
\hline
\end{tabular}

\footnotetext{
* Results of these specimens were not included in the mean lives.
} 


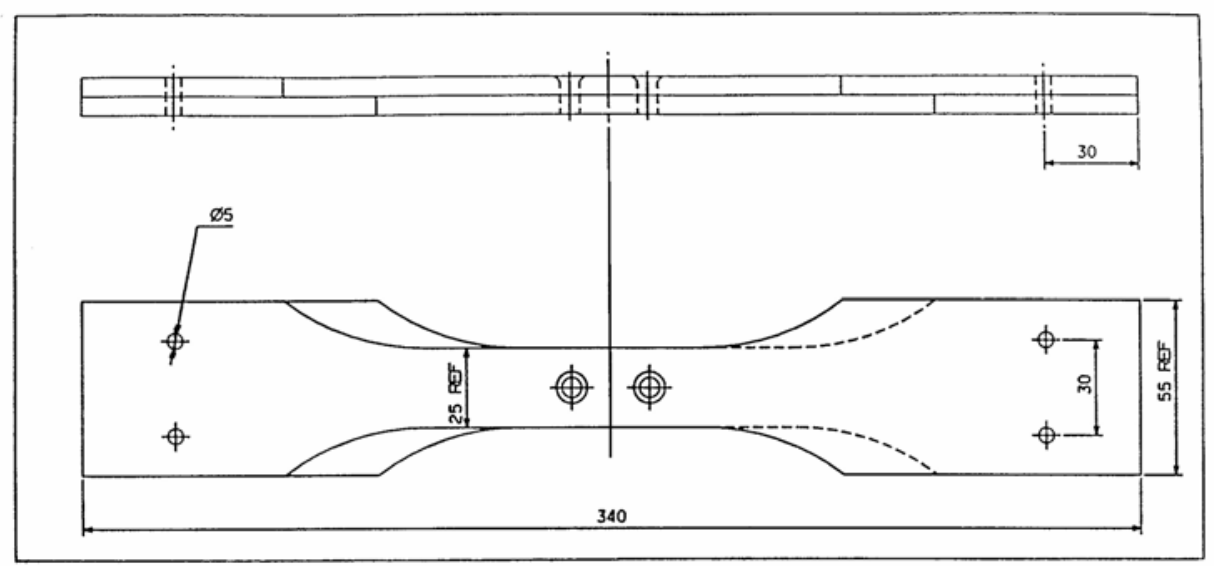

Fig. 1 Low Load Transfer Joint (LLTJ) specimen (all dimensions in mm).

The hole dimensions and expansion levels are summarized in Table 2. For the open-hole specimens, the nominal expansion rate was $4.0-4.4 \%$ resulting retained expansion of $2.8-2.9 \%$. For the joint specimens, the starting hole size met the starting hole size requirements by the FTI process specification [2] resulting in average nominal expansion of $4.1 \%$. The plain hole joint specimen hole diameters result in a slight clearance fit $(0.2-0.9 \%)$ when used with a $1 / 4$ inch Hi-Lok fastener. The $\mathrm{Cx}$ at build specimen and fatigueageing specimen initial hole size ranges result in fastener fits varying from a net fit to a slight interference fit ( $0.1 \%$ interference). The fatigue-aged specimens also had a slight interference fit $(0.1-0.3 \%)$ after the cold expansion treatment.

Table 2 Cold expansion results for open hole and LLTJ specimens.

\begin{tabular}{|c|c|c|c|c|}
\hline Specimen type & $\begin{array}{l}\text { Initial hole diameter } \\
\qquad(\mathrm{mm})\end{array}$ & $\begin{array}{c}\text { Mandrel \& } \\
\text { sleeve } \\
\text { diameter } \\
(\mathrm{mm}) \\
\end{array}$ & $\begin{array}{c}\text { Nominal } \\
\text { expansion (\%) }\end{array}$ & $\begin{array}{c}\text { Retained } \\
\text { expansion (\%) }\end{array}$ \\
\hline Open hole (NCx) & $6.001-6.007$ & N/A & N/A & N/A \\
\hline Open hole ${ }^{1}$ & $5.998-6.010$ & 6.25 & $4.0-4.4$ & $2.8-3.2$ \\
\hline Open hole ${ }^{2}$ & $5.992-6.015$ & 6.25 & $3.9-4.4$ & $2.8-3.4$ \\
\hline Joint - J03 & $6.01-6.14$ & 6.25 & $1.8-4.0$ & $1.0-3.0$ \\
\hline Joint $^{1}$ & $5.98-6.01$ & 6.25 & $4.0-4.4$ & $2.7-3.0$ \\
\hline Joint $^{2}$ & $6.39-6.40$ & 6.67 & $4.0-4.1$ & $2.8-3.1$ \\
\hline
\end{tabular}

1. Specimen cold expanded on production excluding specimen J03.

2. Specimen cold expanded after fatigue ageing.

\subsection{Load spectrum}

The FALSTAFF spectrum [13] used in this study is a standard flight-by-flight loading sequence representing the stresses on the lower wing surface near the wing-to-fuselage joint in tactical aircraft. The 
spectrum consists of a uniquely defined sequence of numbers, ranging from 1 to 32, representing the values of peaks and troughs. The complete sequence represents 200 flights and consists of 35,966 turning points. The spectrum is applied by defining the maximum peak stress value and the loading frequency. In this study the tests were conducted with a peak net stress of $300 \mathrm{MPa}$.

\subsection{Measurement of crack length}

Crack lengths were measured through the use of acetate replicas, which were examined under an optical microscope. The procedure consisted of periodically stopping the fatigue testing at the end of a loading block, applying a static load equal to approximately $60 \%$ of the peak load (to increase the visibility of the crack tip), and applying cellulose acetate pieces which were softened with acetone and then applied to the surface of the specimen and bore of the hole. The replicas were then examined under an optical microscope. The crack lengths were tracked on both sides of the specimen as well as within the bores of the holes. The crack length data obtained is considered accurate to within $10 \mu \mathrm{m}$.

\section{Test results}

The baseline life was determined by the total fatigue life of the plain specimens. 3-5 specimens were tested for each case. The logarithm mean life was used for the control case. For example, for the open hole test the mean life for the plain specimens was 8001 flights. Therefore, the $25 \%$ part-life specimens were pre-fatigued for a period of 2000 flights before cold expansion was applied, and the $50 \%$ part-life specimens for 4000 flights, and so forth. The results show that part-life cold expansion offered substantial life improvements, but the actual benefit is dependent upon the degree of pre-cycling. Details are discussed in next section.

For all cold expanded specimens, a noticeable trend is the difference in crack growth between the mandrel entry and exit faces. In all cases cracks grew faster on the mandrel entry face than on the mandrel exit face (Fig. 2). This can be explained by the fact that the mandrel exit face has higher compressive residual stress levels compared to the mandrel entry face [15-17]. The difference in the residual tangential stress at the entry and exit faces has been attributed to the level of retained expansion and to the material volume carried by the mandrel movement [18].

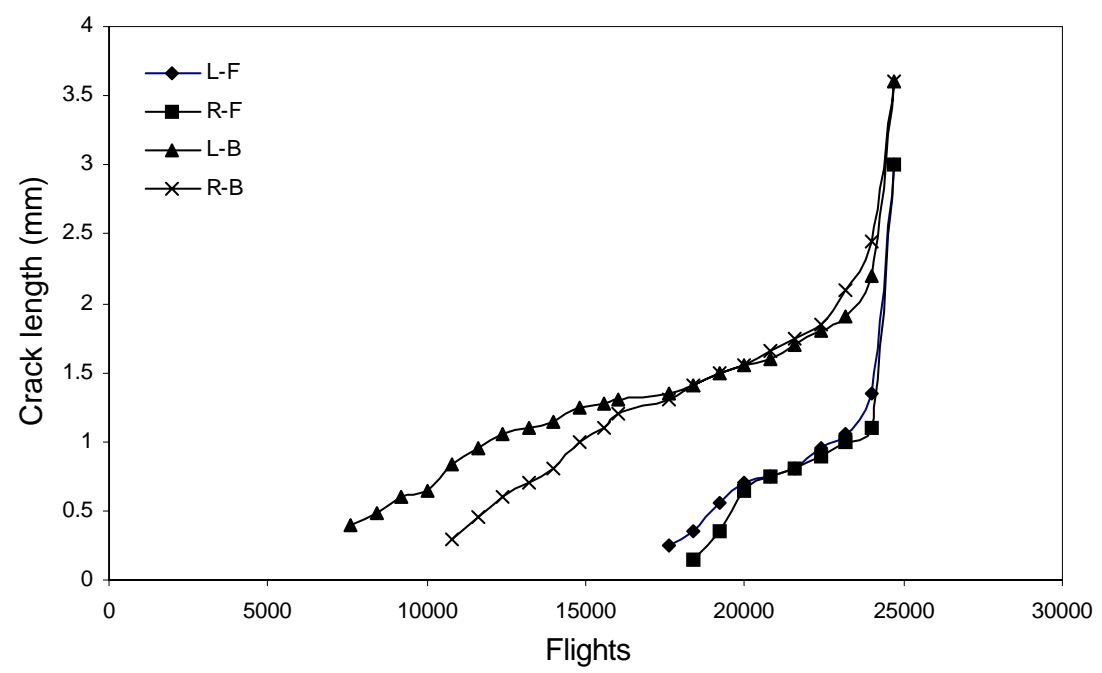

Fig. 2 Crack growth curves from a coldworked hole. Symbols $L$ and $R$ signify the left and right hand sides of the hole, and $F$ and $B$ represent the front and back faces of the specimen. 
For comparison purpose, the total lives of the open hole and joint specimens were plotted with indication of the pre-cycles prior to applying cold expansion in Figs. $3 \& 4$, respectively. The open-hole test result provided the same degree of life improvement for each pre-cycled case when compared with those of the joint specimens. Both tests showed that the cold expansion is most effective at around $25 \%$ of the baseline fatigue life. These life values were based on the mean lives of five tests for each of the test cases of the open hole specimen, but 2-3 samples for the joint specimen at each test condition [9-10].

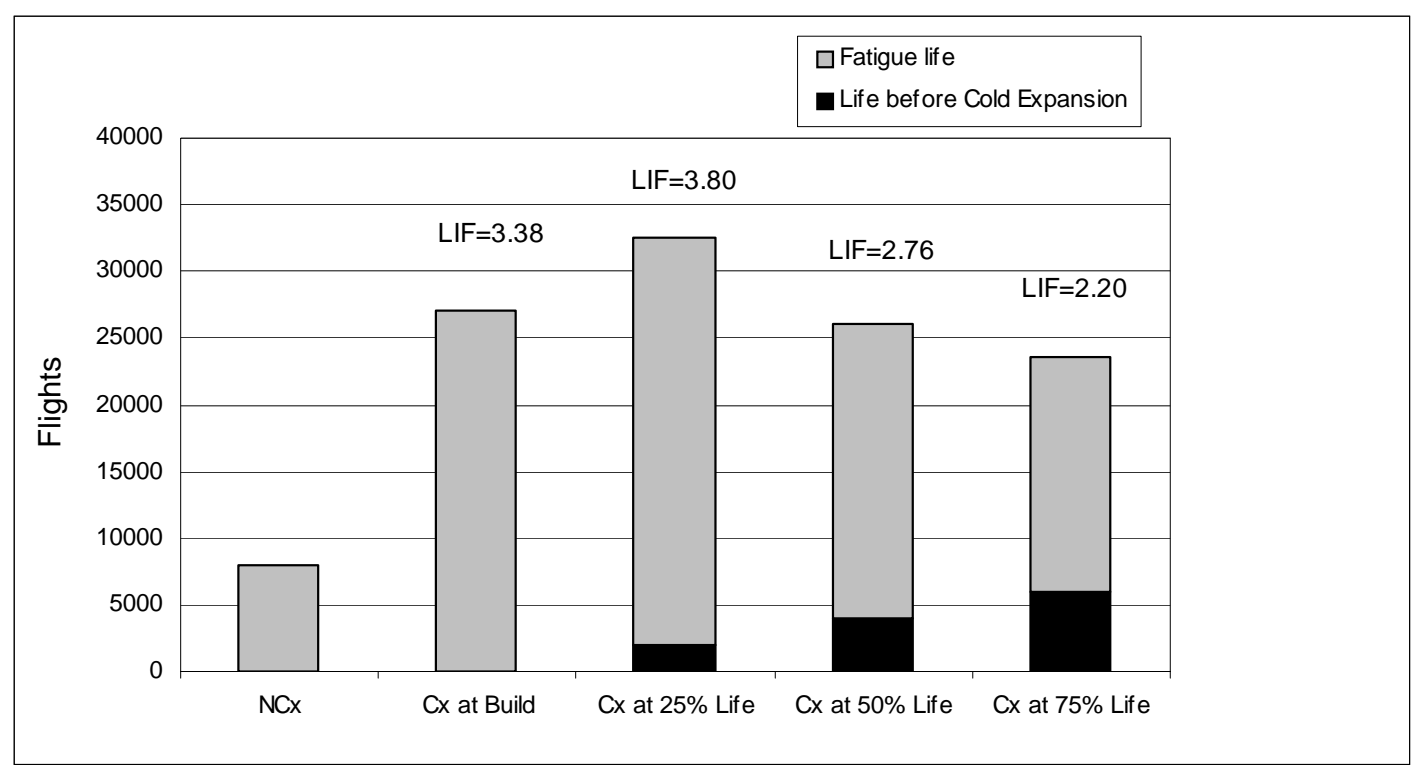

Fig. 3 Comparison of mean fatigue lives and Life Improvement Factors (LIF) for open hole specimens.

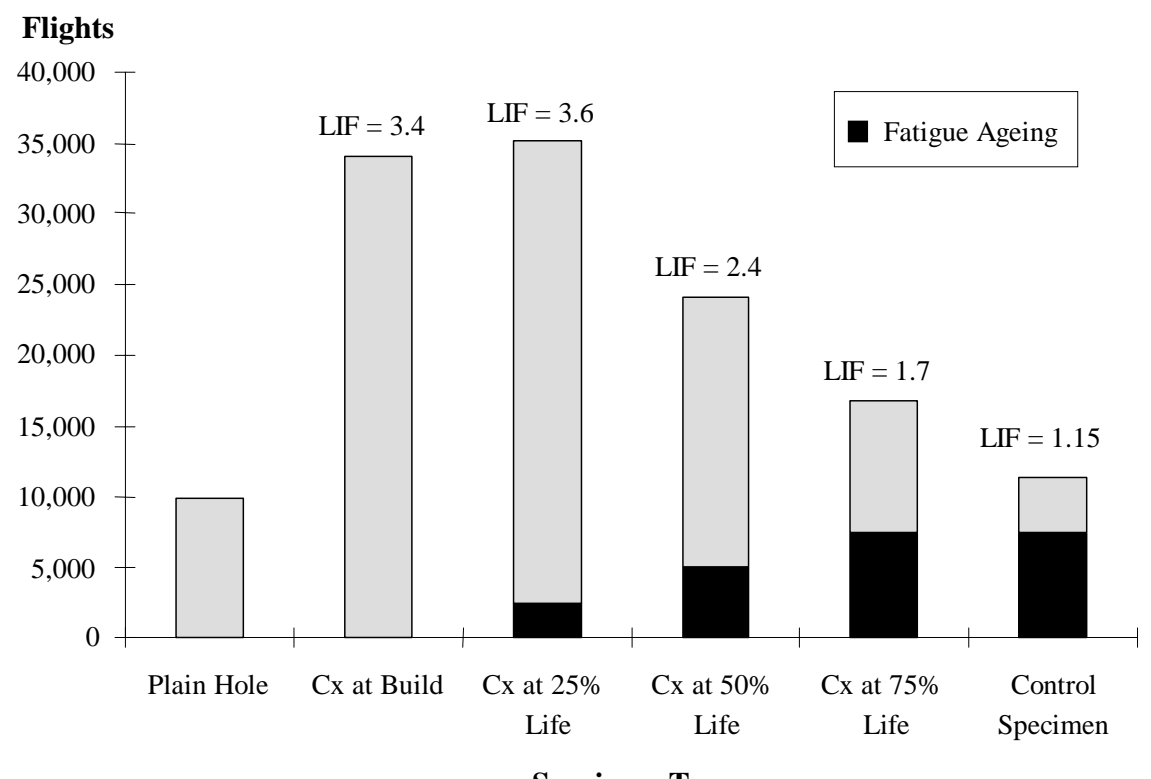

Fig. 4 Comparison of mean fatigue lives and Life Improvement Factors (LIF) for LLT joint specimens 


\section{Prediction of crack growth life}

\subsection{Life prediction model}

It is accepted that the fatigue failure process can be separated into four stages, i.e. crack nucleation, short crack growth, long crack growth, and final fracture. In terms of fatigue lifetime, the entire process corresponds to the so-called total fatigue life. In the field of engineering fatigue analysis, especially aeronautical fatigue analysis, the total fatigue life $\left(N_{t}\right)$ is often divided into two stages, i.e. crack initiation life $\left(N_{i}\right)$ and crack propagation life $\left(N_{p}\right)$ :

$$
N_{t}=N_{i}+N_{p}
$$

Currently $N_{i}$ is calculated by the traditional fatigue analysis using a cumulative damage rule; it includes both crack nucleation and early crack growth lives. $N_{p}$ is predicted by fracture mechanics theory. Definition of crack initiation, which separates the two stages of life, is generally application dependent; it depends on the calculation method for crack initiation life, the volume of data available for subsequent analysis, and also the different points of view. From the crack initiation point of view, this crack length should be around $0.25 \mathrm{~mm}$ [19]. This is because that fatigue analysis for notched parts is based on the local stress-strain approach using the Neuber's rule and material's $S-N$ or $\varepsilon-N$ data. The latter are derived from small coupon samples (usually a bar of $6 \mathrm{~mm}$ in diameter). The fatigue life between the initiation of a $0.25 \mathrm{~mm}$ crack to final fracture is very short for small coupons, e.g. $7 \%$ of the total life [20]. Although the stress gradient of notched samples will change the percentage of crack initiation life, many researchers agree that the initial crack length is between $0.25-0.5 \mathrm{~mm}$ for notched samples [19-20]. On the other hand, the initial crack length should be detectable with high confidence. For example, the SAE has suggested initial crack length of $2.54 \mathrm{~mm}$ (0.1 in) based upon wider experimental research [19]. In the aerospace industry the initial crack length is usually larger than $1.5 \mathrm{~mm}$ to which a design engineer might realistically comprehend or visualise.

Therefore we define two initial crack lengths: initial crack length $a_{i}$ that is initiated due to fatigue cumulative damage mechanism and is the starting crack length for subsequent fracture mechanics analysis, and minimum detectable crack length $a_{d}$ that is the initial crack length in engineering design and analysis. We also define a critical crack length, $a_{c r}$, at which fast fracture occurs. $N_{i}$ is defined as the crack initiation life from the first load cycle to the formation of a detectable crack length $\left(a_{d}\right)$, and $N_{p}$ the crack propagation life from $a_{d}$ to $a_{c r}$. Therefore the crack initiation life $N_{i}$ is calculated in two steps:

$$
N_{i}=N_{a i}+N_{a d}
$$

Where $N_{a i}$ is the life to nucleate a short crack $\left(a_{i}\right)$, and $N_{a d}$ the early crack growth life from $a_{i}$ to $a_{d}$. Life $N_{a i}$ can be calculated by the classic fatigue theory using the material's fatigue data and a cumulative damage rule. The early crack growth life $N_{a d}$ is calculated by the Linear Elastic Fracture Mechanics (LEFM). In this work we have assumed $a_{i}=0.5 \mathrm{~mm}$ and $a_{d}=1.5 \mathrm{~mm}$. As mentioned previously the fraction of life consumed during crack initiation is not a distinct value therefore the decision on the crack lengths $a_{i}$ and $a_{d}$ is somewhat arbitrary. However, the values defined here are within the range for aeronautical fatigue analysis.

With reference to aircraft fatigue the above assumptions define two distinct stages in the fatigue lifetime: $N_{i}$ is the so-called "safe-life" period where no inspection is required, and $N_{p}$ is the crack growth life that can be used for the damage tolerance design and structural inspection programmes. Fig. 5 illustrates this concept, by which more accurate prediction of crack initiation life may be achieved because $N_{i}$ is calculated by a combined fatigue and fracture mechanics analysis.

The crack nucleation life $N_{a i}$ is dominated by shear deformation and is usually predicted by empirical approaches that correlate experimental data into either $S-N$ or $\varepsilon-N$ curves and then use a cumulative damage rule. Some models were described by various investigators [19-20]; both studies used the initial crack length of $0.25 \mathrm{~mm}$. Using this classic fatigue approach the cyclic stress (or strain) range is the dominant variable for damage accumulation. The coldwork process does reduce the cyclic mean stress 
near the hole edge, but the stress range is about the same as that of a plain hole. Therefore, although coldwork increases crack initiation life, the life improvement in this stage is marginal. In fact many tests have shown that cold expansion has little effect on crack nucleation life for the following reason. The beneficial residual stress introduced by cold expansion process is the tangential stress component that is acting along the loading direction and perpendicular to a mode I crack. However, crack nucleation and early growth appear to be dominated by local shear deformation and the initial short crack tends to be about $45^{\circ}$ to the loading direction. The classic fatigue analysis has difficulty to predict the coldwork effect.

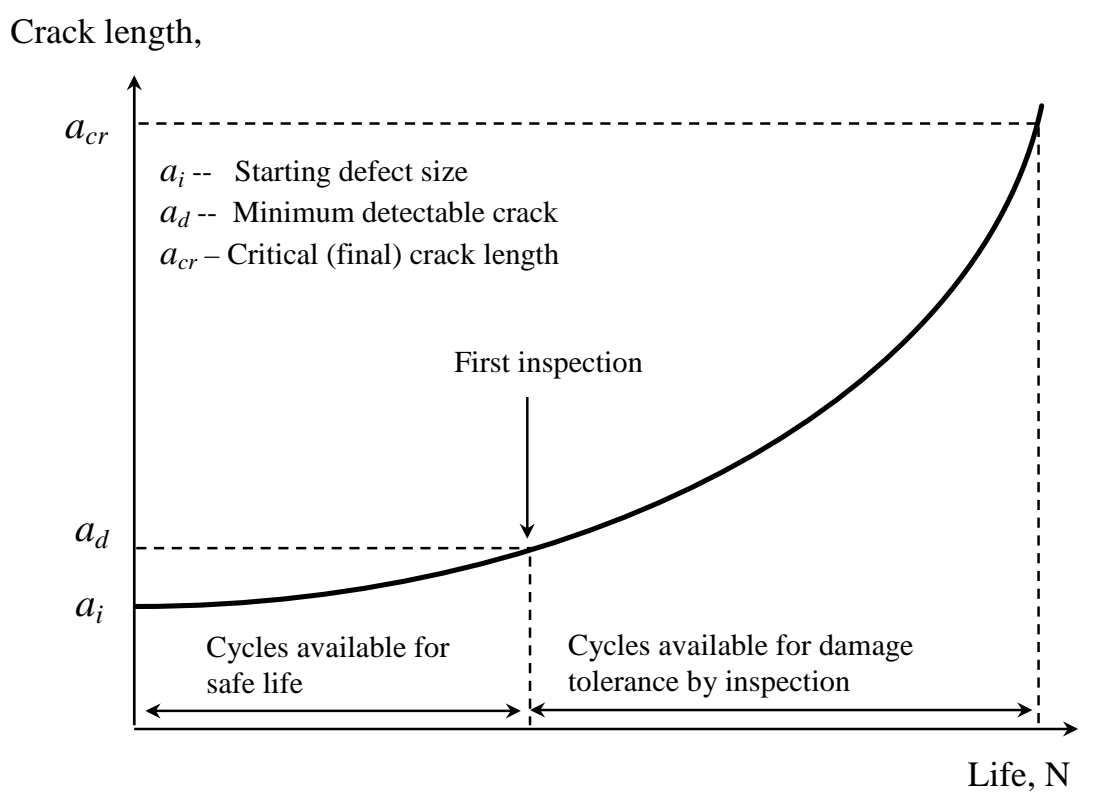

Fig. 5 Schematic of the total life concept with definitions on different initial crack lengths.

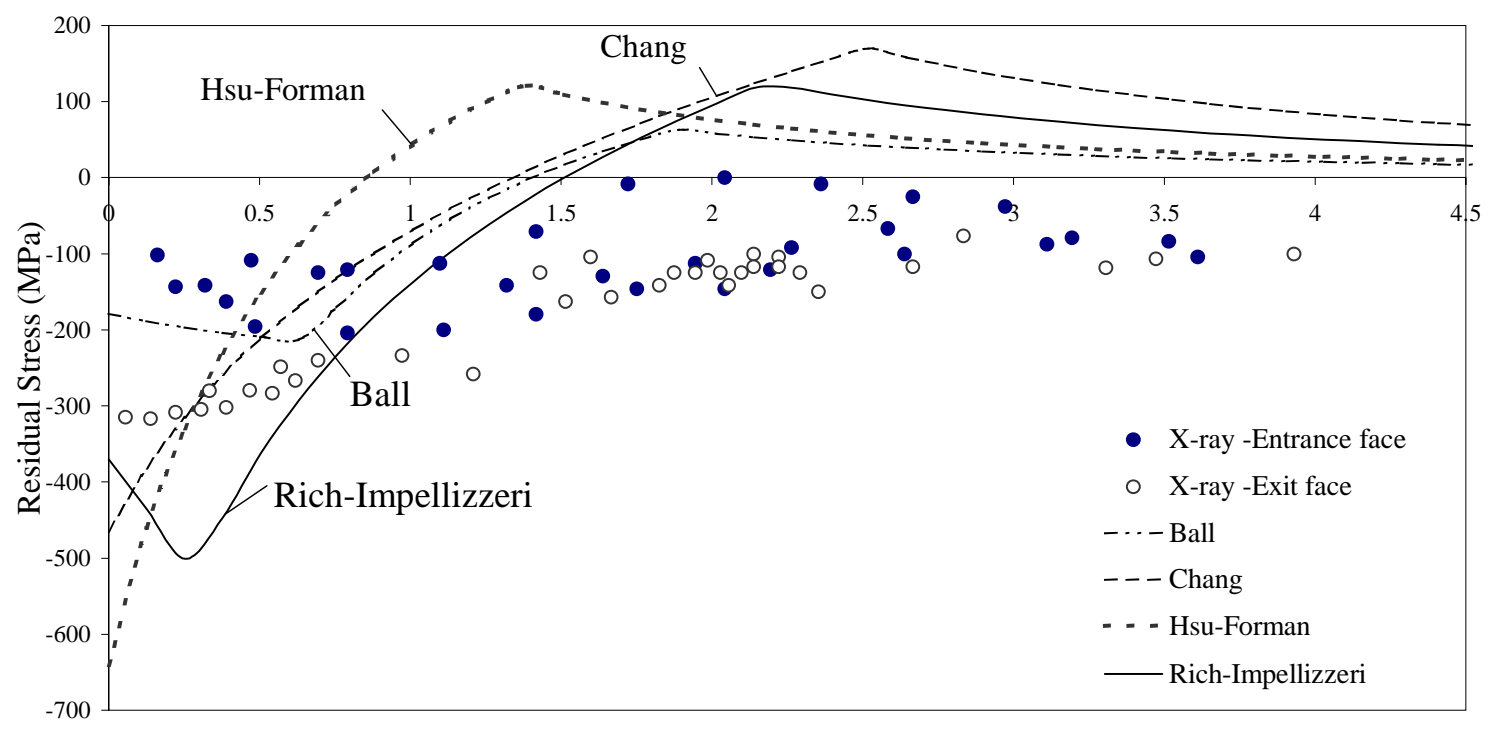

Normalised distance from hole edge, $r / R$

Fig. 6 Residual stress distributions determined by different closed-form models and compared with an X-ray diffraction test.

In this paper fatigue lifetime to develop a detectable crack $a_{d}$ is predicted in two steps, $N_{a i}$ and $N_{a d}$; the latter is calculated by the LEFM theory. The benefit of doing so is clear. The coldwork-induced tangential 
stress is compressive near the hole edge within the distance of 1-2 times of the hole radius (Fig 6). Consequently, crack growth rate will be reduced when a crack is in that region. Fracture mechanics method can predict this effect using a superposition of residual stress intensity and the stress intensity resulting from the applied load [20]. Using the cumulative damage approach to calculate the initiation of a larger detectable crack will not predict this beneficial effect of coldwork. On the other hand, crack growth life under spectrum loading is considerably different from that under constant amplitude testing. In general crack growth represents a larger percentage of spectrum test life because of the crack growth retardation effects due to intermittently applied high tensile load cycles. Again, fracture mechanics can predict this effect in the early crack growth stage, i.e. $a_{i}$ to $a_{d}$.

This paper focuses on predicting crack growth life with cold expansion effect; the crack nucleation life for cold worked holes $N_{a i}$ (to initiate $a_{i}$ ) is obtained directly from the test results.

\subsection{Crack growth life prediction}

In this study fatigue life prediction was performed for the open-hole specimen since it's easier to measure the crack length against the load histories. The analysis used an existing analytical solution for the residual tangential stress and the LEFM theory for predicting crack propagation. Firstly, four closed-form residual stress models were studied. They are the plane-stress models proposed by Hsu-Forman [21] and Ball [22], and plane-strain models by Rich-Impellizzeri [20] and Chang [23]. For the open hole specimen, the residual stress distributions described by these analytical models showed considerable differences in terms of stress profile, reverse yield zone size and the maximum residual stress. Since the thickness of the specimen was $6 \mathrm{~mm}$, which fits in neither the plane-stress nor the plane-strain condition, differences were expected and some modification was necessary in order to use these models. A comparative study of these models was carried out based on life prediction results of three different tests, and necessary modifications mainly for the work hardening and the Bauschinger effects were suggested [24]. For the open-hole specimen of this study calculated residual tangential stress profiles using the modified closedform solutions are given in Fig. 6. Measured residual stress distributions are included in the plot showing reasonable agreement with the Ball's and Chang's models near the hole region. The measurement was made by the X-ray diffraction technique [17], in which the same material (2024-T351), same dimensions, and same degree of cold-expansion were used except that the specimens in [17] were much wider than that of this study. However, this should not affect the residual stress distributions near the hole edge.

To account for the effect of residual stresses, the effective stress intensity factor, $K_{\text {eff }}$, is determined by [20]:

$$
K_{\text {eff }}=K_{\text {appl }}+K_{\text {res }}
$$

where, $K_{a p p l}$ is the stress intensity factor due to applied stresses, and $K_{\text {res }}$ the stress intensity due to the residual stress field. Crack growth rate is determined by a Paris type law using the effective stress intensity range [20]:

$$
\frac{d a}{d N}=f\left(\Delta K_{e f f}\right)
$$

The analysis was performed by the AFGROW computer code [25], which has the facility to calculate the residual stress intensity and the effective stress intensity factors. The users can simply input the known residual stress distributions through a dialog window. There are two methods available in the AFGROW to calculate the residual stress intensity factors. They are the Gaussian integration and the weight function method [25]. The Gaussian integration method was used in this study.

The geometrical model used was a double corner crack emanating from a central hole. Crack only grew on one face of the specimen, however it did give control over the lengths of the surface crack length and through-thickness crack. The crack grew symmetrically on either side of the hole and, once a throughthickness crack was achieved, the crack front became straight. Although this may not simulate the initiation or early corner crack pattern of the experimental specimens, it was thought to be adequate when 
using the average crack length from both sides. A new model option is now available in the new version of AFGROW that allows cracks to be initiated on both faces of the specimen and that may have addressed some of these issues. However, this function was not operational in the version when this study was made.

\subsection{Prediction results}

The initial crack size $\left(a_{i}\right)$ was set at $0.5 \mathrm{~mm}$ to correlate with the experimental data and corner crack aspect ratio was set at 1 . To initiate a $0.5 \mathrm{~mm}$ crack, approximately 7370 and 11340 flights were needed for the plain and $\mathrm{Cx}$ holes, respectively. Therefore these flights were taken as the lives $\left(N_{a i}\right)$ for initiating $a_{i}=0.5 \mathrm{~mm}$. The life to initiate a $0.5 \mathrm{~mm}$ crack is considerably longer for the Cx specimens, but the life improvement at this stage is not as significant as the published life improvement in the total fatigue life for reasons discussed in Section 4.1. The life to develop a detectable crack length $a_{d}$ is the sum of $N_{a i}$ and $N_{a d}$; the latter is predicted by the AFGROW code. To account for the overload retardation effect, the Willenborg model was employed.

The predicted crack growth lives are given in Figs. 7 and 8 (smooth lines) for the plain and cold expanded specimens, respectively. The experimentally measured crack growth histories are also shown in the figures (scattered symbols). Symbols $L$ and $R$ signify the left and right hand sides of the hole when viewed from the front when the specimen was in the test machine, while $F$ and $B$ represent the front and back faces of the specimen. Each figure shows four experimental tests, and every corner crack is included. Based on our previous work [10, 24], the Ball's residual stress model [22] was used for residual stress calculation. These figures show that the computer simulation not only predicted the average lives correctly, for both plain and cold-expanded holes, but also mimicked the crack growth histories reasonably well. Life improvement was found mainly in the crack initiation life $\left(N_{i}\right)$ under the assumption of a detectable initial crack $a_{d}=1.5 \mathrm{~mm}$. Since the specimen was narrow (25 mm wide) and the critical crack length was about $3.6 \mathrm{~mm}$, the benefit of the residual compressive tangential stress (within $4 \mathrm{~mm}$ from the hole edge) was not fully used in the crack growth stage.

The strategy of combining a fracture mechanics computer code and an existing residual stress model should also work for fastener holes with cold expansion effect. AFGROW is capable of taking the bearing load into account when calculating the stress intensity factors. This part of work is currently in progress.

For the part-life cold expanded cases, the prediction was less clear and required separate correlation for each level of pre-fatigue. The scatter in the test data, primarily in the different lengths and growth rates of the separate corner cracks for each specimen, made the prediction work difficult. While correlation was primarily made with regard to the dominant crack, this was not necessarily representative of the crack growth for the whole specimen. In this study, we have used the life to initiate a $0.5 \mathrm{~mm}$ crack after the part-life $\mathrm{Cx}$ as the starting point of the AFGROW prediction work. The prediction routine is the same as for the cold expansion at build case. Details of the prediction results

In general, the test program is believed to have been successful in demonstrating that useful life improvements can be obtained when cold expansion is applied at various stages in the fatigue life of a component that is loaded under an aircraft representative loading spectrum. The life prediction analysis is promising, with quite reasonable correlation in crack growth life for the $0 \% \mathrm{Cx}$ and $25 \% \mathrm{Cx}$ groups but generally becoming un-conservative as the amount of pre-fatigue cycles increased [26]. 


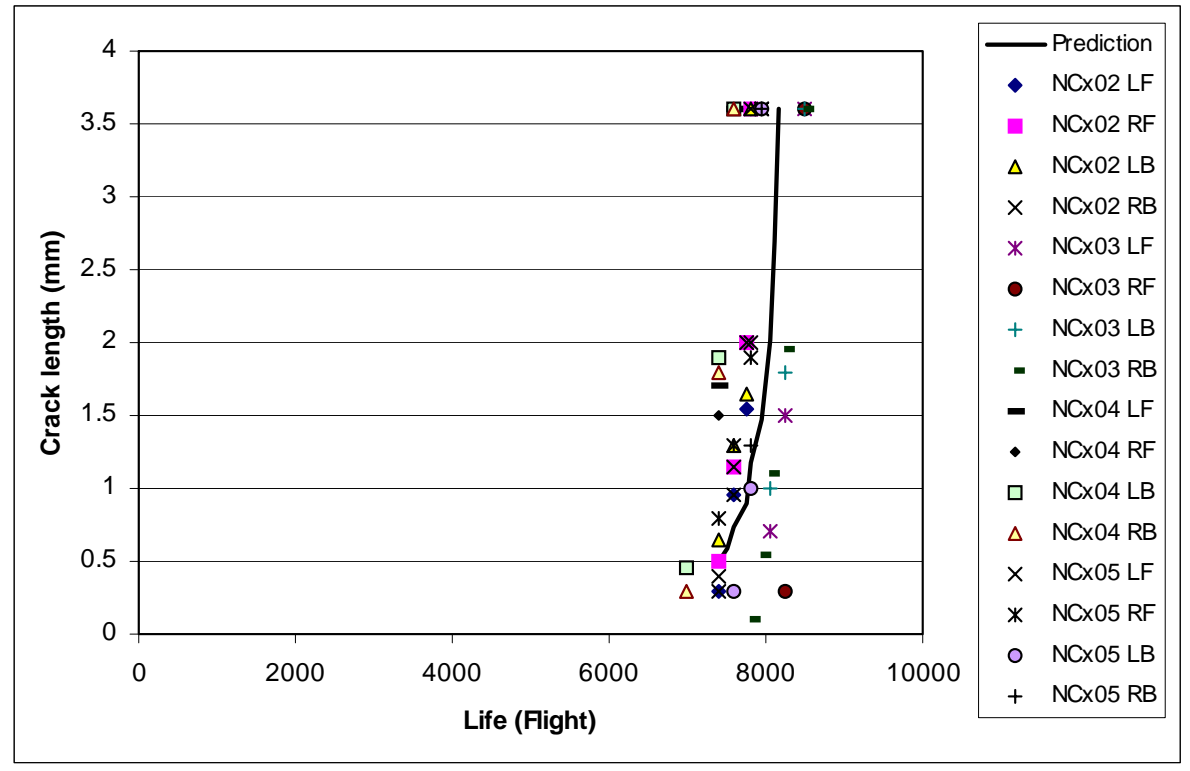

Fig. 7 Crack growth histories for plain specimens - AFGROW prediction vs. experimental results

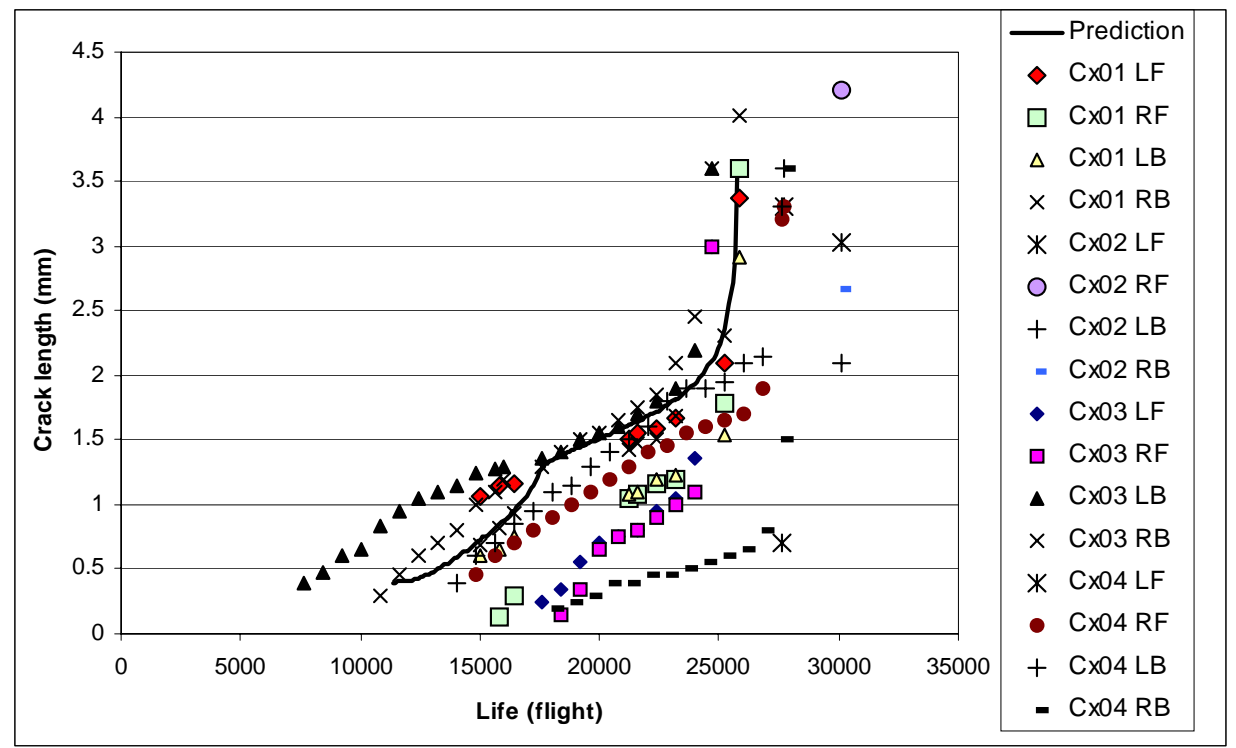

Fig. 8 Crack growth histories for cold expanded specimens AFGROW prediction vs. experimental results.

\section{Conclusions}

Part-life cold expansion provides significant life extension compared to a non-cold expanded (NCx) baseline life. This applies for all pre-fatigue levels from $25 \%$ up to $75 \%$. The life improvement factor (LIF) for the total fatigue life ranged from 3.8 (25\% Cx) down to 2.2 (75\% Cx). The $25 \%$ pre-fatigue level Cx returned the greatest improvement in both total life and crack nucleation life $\left(N_{a i}\right)$.

There was a significant and steady decrease in the life to initiation a crack from the $25 \% \mathrm{Cx}$ specimens to the $75 \% \mathrm{Cx}$ specimens. This was possibly due to some small cracks not being completely removed by the cold expansion and reaming process. However, for the $\mathrm{Cx}$ at build specimens cracks initiated slightly 
quicker than both the $25 \% \mathrm{Cx}$ and 50\%Cx groups, even when the 'baseline' effect of the Cx process was considered by subtracting the pre-fatigue life from the part-life specimens' initiation life.

The benefits of cold expansion were due primarily to the decrease in crack propagation rate in the early crack growth stage $(0.5-1.5 \mathrm{~mm})$. For these narrow-width specimens, the life improvement is mainly in the initiation of a detectable crack with only marginal improvements in the longer crack growth life.

For all specimens, the critical cracks were at the mandrel entry face where the residual compressive stresses were lower compared to the mandrel exit face.

When the benefit is measured by the life improvement factor (LIF), open hole specimens can predict the benefits of cold expansion in the low-load transfer joints if the degree of cold expansion is the same. However, this conclusion may not hold for the mid-load or high-load transfer joints when significant secondary bending is present.

The strategy of splitting fatigue life into two stages and the proposed prediction method worked well. For the plain and $\mathrm{Cx}$ at build cases, the predictions agreed well with the tests in the two crack growth stages, $N_{a d}$ and $N_{p}$.

\section{Acknowledgements}

The authors are grateful to QinetiQ (formerly Defense \& Evaluation Research Agency) for supporting the fatigue test. We also acknowledge Major J Gaerke for providing validation data for the joint specimens and Capt A MacKenzie for performing part of the life prediction tasks.

\section{References}

1. Buxbaum $\mathrm{O}$ \& Huth $\mathrm{H}$. Expansion of cracked fastener holes as a measure for extension of lifetime to repair. Engineering Fracture Mechanics. 1987: 28: 689-698.

2. Phillips JL. Sleeve coldworking fastener holes, Air Force Materials Laboratory Report, AFML-TR-7410, Vol. 1, 1974.

3. Landy MA \& Champoux RL. FTI Engineering Process Specification FTI 8101B - Cold Expansion of Fastener and Other Holes Using the Split Sleeve System (CX) and Countersink Cold Expansion Nosecap (CCX), Fatigue Technology Inc., Seattle, Washington, USA, 1984.

4. Reid L. Split sleeve cold expansion as a rework process for previously cold expanded holes. ICAF'93 International Committee on Aeronautical Fatigue, Stockholm, Sweden, Jun 7-11, 1993.

5. Ball DL \& Lowry DR. Experimental investigation on the effectiveness of cold expansion of fastener holes. Fatigue \& Fract of Eng. Materials \& Structures, 1998: 21: 17-34.

6. Wagner RV, Reid L, Easterbrook ET and Rufin AC. Beneficial effects of split sleeve cold expansion ${ }^{\mathrm{TM}}$ on the fatigue lives of pre-cycled cold expanded structure. 1992 USAF Aircraft Structural Integrity Program Conference, San Antonio, TX, December 1992.

7. Cook R. Repair of cracked holes using cold expansion. Computer Methods and Experimental Measurements for Surface Treatment Effects, Ed. Aliabadi MH \& Brebbia CA, Computational Mechanics Publications, 1997.

8. Gaerke JG. Fatigue Life Extension Through Cold Expansion. MSc Thesis, College of Aeronautics, Cranfield University, 1998.

9. Gaerke JG \& Zhang X. Fatigue Life Extension Through Cold Expansion. Proceedings of the CEAS Forum on Life Extension - Aerospace Technology Opportunities, Cambridge, UK, 23-25 March 1999, Paper 28.

10. Gaerke JG, Zhang X \& Wang Z. Life enhancement of fatigue aged fastener holes using cold expansion process, Proc Instn Mech Engrs Part G: J of Aerospace Engng. 2000: 214: 281-293.

11. Fatigue of Aluminium Alloy Joints with Various Fastener Systems, Low Load Transfer, ESDU Item No. 89046, Engineering Sciences Data Unit International plc, 1989. 
12. Cook R. Standard Fatigue Test Specimens for Fastener Evaluation. AGARD-AG-304, Advisory Group for Aerospace Research and Development, 1987.

13. Van Dijk GM \& de Jonge JB. Introduction to a Fighter Aircraft Loading Standard for Fatigue Evaluation, NLR MP 75071, National Aerospace Laboratory NLR, Netherlands, 1975.

14. Standard Test Method for Measurement of Fatigue Crack Growth Rates - E647. 1994 Annual Book of ASTM Standards, Vol. 03.01, American Society for Testing and Materials, 1994: 569-596.

15. Cook R \& Holdway P. Residual stresses induced by hole cold expansion. Computer Methods and Experimental Measurements for Surface Treatment Effects, Proc $1^{\text {st }}$ Int. Conf. (Edited by Aliabadi MH \& Brebbia CA). Computational Mechanics Publications, Southampton, UK, July 1993, 91-100.

16. Bernard M, Bui-Quoc T \& Burlat M. Effect of re-coldworking on fatigue life enhancement of a fastener hole. Fatigue Fract. Engng. Mater. Struct. 1995: 18(7/8): 765-775.

17. Priest M, Poussard CG, Pavier MJ \& Smith DJ. An assessment of residual stress measurements around cold-worked holes. Experimental Mechanics, 1995: 361-366.

18. Forgues, FA, Bernard, M, Bui-Quoc, T. 3-D axisymmetric numerical analysis and experimental study of the fastener hole coldworking process. Computer Methods and Experimental Measurements for Surface Treatment Effects, Proc $1^{\text {st }}$ Int. Conf. (Edited by Aliabadi MH \& Brebbia CA). Computational Mechanics Publications, Southampton, UK, July 1993, pp. 61-70.

19. Glinka G \& Stephens RI. Total fatigue life calculations in notched SAE 0030 cast steel under variable loading spectra. Fracture Mechanics: Fourteenth Symposium - Volume I: Theory and Analysis, ASTM STP 791, 1983: I-427 - I-445.

20. Rich DL \& Impellizzeri LF. Fatigue analysis of cold-worked and interference fit fastener holes. Cyclic Stress-Strain and Plastic Deformation Aspect of Fatigue Crack Growth, ASTM STP 637, Amer. Soc. for Test and Mat. 1977: 153-175.

21. Hsu YC \& Forman RG. Elastic-plastic analysis of an infinite sheet having a circular hole under pressure. ASME J. Applied Mechanics, 1975: 42: 347-352.

22. Ball DL. Elastic-plastic stress analysis of cold expanded fastener holes. Fatigue Fract. Engng. Mater. \& Struct., 1995: 18: 47-63.

23. Chang JB. Prediction of fatigue crack growth at cold-worked fastener holes. J of Aircraft, 1977: 14: 903908.

24. Wang Z \& Zhang X. A study on predicting fatigue crack growth life for cold-worked holes based on different closed-form residual stress models. Int Conf on Fatigue Damage of Structural Materials IV, Hyannis, 2002. (To be published in the same Issues of Int J Fatigue as this paper)

25. Harter JA, AFGROW Users Guide and Technical Manual, AFRL-VA-WP-1999-3016, Air Force Research Laboratory, Wright-Patterson, OH, Feb 1999.

26. AP MacKenzie. Fatigue life benefits of part-life cold expansion. MSc Thesis, College of Aeronautics, Cranfield University, 2000. 